\title{
Frequency of Fibromyalgia in a Sample of Iraqi Patients in Mosul with Ischemic Heart Disease
}

\author{
Ali Younis*(i), Mohammad Harith Alsaaty (D) \\ Department of Medicine, College of Medicine, University of Mosul, Mosul, Iraq
}

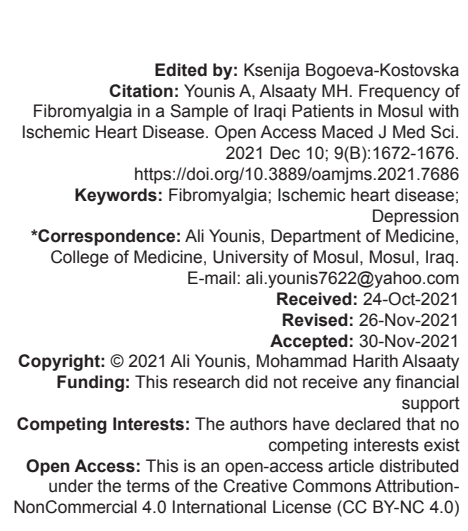

\section{Introduction}

Fibromyalgia is a disorder characterized by chronic widespread musculoskeletal pain often associated with unrefreshing sleep, debilitating fatigue, cognitive disturbance, multiple somatic symptoms, anxiety, and depression [1], [2]. The syndrome's etiology is unclear and the pathophysiology is uncertain [1], [2]. However, pain amplification and psychological distress are the two intrinsic mechanisms associated with the risk of developing fibromyalgia [3], [4]. The fibromyalgia prevalence is $2-4 \%$ and increases with age, reaching a peak between 60 and 79 years. Women are 6 times more commonly diagnosed with fibromyalgia than men [5]. There is a well-documented association between ischemic heart disease (IHD) and depression [6], and claims have been made about the impact of depression on major outcomes, such as mortality [7]. Psychiatric diseases (major depressive disorder and anxiety disorder) are common comorbidities in patients with fibromyalgia [8]. However, IHD has seldom been associated with fibromyalgia. On the other hand, few studies have shown that patients with fibromyalgia have a higher subsequent risk of IHD events [9], [10].

The present study aimed to assess the frequency of fibromyalgia in patients with IHD and to evaluate the characteristics of IHD patients with comorbid fibromyalgia.

\section{Patients and Methods}

This case-control study was conducted on 100 patients with IHD in the coronary care unit (CCU), Department of Medicine in Ibn Sina Teaching Hospital in Mosul City, between March and November 2020. The study was conducted in keeping with the principles stated in the Helsinki declaration, and before the study, written informed consent was obtained from all participants. The study protocol was approved by the Department of Medicine, College of Medicine, University of Mosul (approval date: 28/08/2020, no: MDESC8-2). Written informed consent was obtained from all participants. 
Eligible patients were $\geq 18$ years old of either gender, with a history of IHD, who were currently admitted to the CCU and diagnosed as an acute coronary syndrome based on clinical features, electrocardiography, and/ or cardiac enzymes. All those patients were evaluated before their discharge from the hospital.

Patients were excluded from the study if they had symptoms of fibromyalgia before the diagnosis of IHD. Patients were also excluded if they had inflammatory arthropathy, connective tissue disease, thyroid disease, osteomalacia, or established malignancy by history and clinical examination. For comparative purposes, 100 healthy individuals were collected from the relatives of patients attending the hospital. Patients and controls were age and sex-matched. Data collection was carried out through a direct face-to-face interview using a clinical study form sheet containing a questionnaire.

All the patients had their socio-demographic data recorded (age, gender, body mass index [BMI], employment, and marital status). In addition, medical history, duration of IHD, previous coronary angiography, and/or percutaneous coronary interventions (PCl), and drug therapy were recorded accordingly.

Blood tests including (complete blood count, blood biochemistry, thyroid function test, Vitamin D level, and serological and inflammatory markers), radiographs and/or other tests were performed for both groups if indicated and based on the clinical situation.

The diagnosis of fibromyalgia was done according to the 2011 modification of the 2010 American College of Rheumatology preliminary diagnostic criteria for fibromyalgia by one rheumatologist [11]. According to these criteria, a patient meets fibromyalgia diagnostic criteria if the following three elements are present:

- $\quad$ "Widespread pain index (WPI) >7 and symptom severity (SS) scale $>5$ or WPI 3-6 and SS scale $>9$ "

- $\quad$ Symptoms have been present for at least 3 months

- $\quad$ There is no other condition that could account for the patient's symptoms.

The WPI is a tool that counts the number of painful bodily locations among a set of 19 areas. The SS score includes an assessment of fatigue, waking unrefreshed, and cognitive problems, as well as the total number of somatic symptoms [11].

Echocardiography was performed for all patients and left ventricular ejection fraction (LVEF) was estimated. All the patients were evaluated for the presence of depression using the beck depression inventory (BDI), which is a 21-item survey that assesses the presence and severity of depression. BDI consists of 21 questions and each question could be answered with a score that ranged from 0 to 3 (absent, mild, moderate, and severe), allowing to determine the intensity of the symptom. Therefore, the total BDI score can be between 0 and 63 points. The standard cutoff scores are as follows: 0-9: Indicates minimal depression; 10-18: Indicates mild depression; 19-29: Indicates moderate depression; and 30-63: Indicates severe depression [12]. The validated Arabic forms of BDI were filled by patients themselves [13]. However, for those who were unable to do the test, due to poor vision or literacy issues, an alternative method was used. The interviewer would read the inventory allowing the patients to respond by indicating the statements which best described how they felt over the past week.

Statistical analyzes were done using Statistical Package for the Social Sciences, version 23. Continuous variables were expressed as mean \pm standard deviation. Chi-square test was used for the comparison of qualitative data. The Student (t-test) was used to calculate the differences between the two means. The multivariate logistic regression analysis was used to predict the probability of the significant independent variable under the study. $P<0.05$ was considered to be statistically significant.

\section{Results}

One hundred patients with IHD, 42 males $(42 \%)$ and 58 females $(58 \%)$, their mean age was $(54.57 \pm 8.64)$ years, and 100 healthy control group, 44 males $(44 \%)$ and 56 females (56\%), their mean age was $(55.86 \pm 6.75)$ years were included in this study. Both groups were age and sex-matched, with no significant statistical difference between them ( $p>0.05)$.

The frequency of fibromyalgia in patients with IHD was $(29 \%)$ compared to $(7 \%)$ in healthy individuals $(p=0.00005)$ indicating a statistically significant difference between both groups as shown in Table 1.

Table 1: Comparison of fibromyalgia between patients with IHD and healthy control group

\begin{tabular}{llll}
\hline Fibromyalgia status & Cases (IHD) $\mathrm{n}=100$ & Controls (no IHD) $\mathrm{n}=100$ & $\mathrm{p}$-value \\
\hline Fibromyalgia, $\mathrm{n}(\%)$ & $29(29)$ & $7(7)$ & 0.00005 \\
No fibromyalgia, $\mathrm{n}(\%)$ & $71(73)$ & $93(93)$ & \\
\hline
\end{tabular}

The socio-demographic features of IHD patients with and without fibromyalgia are shown in Table 2. The mean age and percentage of women were significantly higher in IHD patients with fibromyalgia than without fibromyalgia. Other socio-demographic features including BMI, marital status, and employment status were not significantly different between the groups.

Table 2: Socio-demographic features of IHD patients with and without fibromyalgia

\begin{tabular}{llll}
\hline Variable & $\begin{array}{l}\text { IHD patients with } \\
\text { fibromyalgia } \mathrm{n}=29\end{array}$ & $\begin{array}{l}\text { IHD patients without } \\
\text { fibromyalgia } \mathrm{n}=71\end{array}$ & p-value \\
\hline Mean age, years & $57.3 \pm 7.84$ & $53.45 \pm 8.76$ & 0.04 \\
Gender $(\mathrm{F} / \mathrm{M}), \mathrm{n}(\%)$ & $23 / 6(79.3 / 20.7)$ & $35 / 36(49.3 / 50.7)$ & 0.006 \\
BMI $\left(\mathrm{kg} / \mathrm{m}^{2}\right)$ & $24.9 \pm 3.8$ & $25.5 \pm 4.3$ & 0.51 \\
Married, $\mathrm{n}(\%)$ & $24(82.76)$ & $54(83.1)$ & 0.46 \\
Employed, $\mathrm{n}(\%)$ & $11(37.9)$ & $24(33.8)$ & 0.69 \\
\hline BMl: Body mass index. & & &
\end{tabular}


The characteristics of IHD patients with and without fibromyalgia are shown in Table 3. Fibromyalgia was found to be more common in patients with the present myocardial infarction $(p=0.032)$ and in patients who had a previous coronary angiography (0.008), whereas there was no difference with regards to disease duration, family history of IHD, diabetes mellitus, and use of statins ( $p>0.05$ for all). Patients with comorbid fibromyalgia had lower LVEF $(p=0.0003)$ and significantly higher scores on BDI ( $p=0.0025)$.

Table 3: Characteristics among IHD patients with and without fibromyalgia

\begin{tabular}{|c|c|c|c|}
\hline Variable & $\begin{array}{l}\text { IHD patients with } \\
\text { fibromyalgia } n=29\end{array}$ & $\begin{array}{l}\text { IHD patients without } \\
\text { fibromyalgia } n=71\end{array}$ & $p$-value \\
\hline $\begin{array}{l}\text { Duration of IHD, } \\
\text { years }\end{array}$ & $4.45 \pm 3.26$ & $4.86 \pm 4.05$ & 0.6292 \\
\hline Use of statins (\%) & $20(68.96)$ & $49(69.01)$ & 0.996 \\
\hline $\begin{array}{l}\text { Diabetes mellitus, } \\
\mathrm{n}(\%)\end{array}$ & $11(37.9)$ & $26(36.6)$ & 0.901 \\
\hline $\begin{array}{l}\text { Family history of } \\
\text { IHD, } n(\%)\end{array}$ & $11(37.93)$ & $29(40.85)$ & 0.787 \\
\hline $\begin{array}{l}\text { Previous coronary } \\
\text { angiography, } \mathrm{n}(\%)\end{array}$ & $11(37.93)$ & $10(14.08)$ & 00.008 \\
\hline $\begin{array}{l}\text { Present myocardial } \\
\text { infarction }\end{array}$ & $24(82.76)$ & $43(60.56)$ & 0.032 \\
\hline LVEF & $54.5 \pm 8$ & $61.7 \pm 9$ & 0.0003 \\
\hline $\mathrm{BDI}$ & $21.8 \pm 9.2$ & $15.9 \pm 8.4$ & 0.0025 \\
\hline
\end{tabular}

Table 4 shows the result of multivariate binary logistic regression analysis for the significant variables generated during univariate analysis. The proportion of women was significantly higher in IHD with fibromyalgia compared to no fibromyalgia, the estimated odds ratio $(O R)$ is $3.839(p=0.022)$. This finding indicates that fibromyalgia is about 3.8 times more likely to be present in females with IHD, adjusted for other variables in the model. Those IHD patients with comorbid fibromyalgia had significantly lower LVEF with OR 0.917 confidence interval $0.861-0.978, p=0.008$. This indicates that fibromyalgia is more likely to be present in patients with the lower LVEF adjusted for other variables in the model.

\section{Discussion}

In the present study, fibromyalgia was significantly more prevalent among patients with IHD compared to controls ( $29 \%$ vs. $7 \%)$. This finding is in agreement with the previous studies which showed a high frequency of fibromyalgia in IHD. In a study conducted by Al-Bidri et al., the frequency of fibromyalgia in patients with IHD was $18 \%$ compared to $6 \%$ in healthy individuals [14]. In their study, Ablin et al. demonstrated a significantly higher proportion of fibromyalgia among patients with pathological findings on coronary angiography $(33.3 \%)$ compared to patients with normal coronary arteries (13.3\%) and healthy controls (6\%) [15].

Several mechanisms can explain the association between fibromyalgia and IHD. First, the link between IHD and depression has been well documented; depression is associated with negative outcomes such as mortality [16], [17], [18], [19]. It is also well accepted that the prevalence of depression is high in fibromyalgia. Thus, depression by itself can be a predisposing factor to fibromyalgia development in IHD [20]. Second, different forms of trauma have been linked to fibromyalgia development [21]. Both coronary angiography and PCls are invasive and potentially painful procedures. These procedures could act as a physical trauma that triggers the development of fibromyalgia [15]. Third, neuroendocrine and autonomic response to the detrimental effects of IHD can impair cardiac performance [15]. Finally, polypharmacy including statins could be the contributing factor to pain development in IHD patients.

In our study, IHD patients with comorbid fibromyalgia were older and most were women. It is known that the prevalence of fibromyalgia increases with age and that fibromyalgia is more common in women. Multivariate logistic regression analysis revealed that fibromyalgia was about 3.8 times more likely to develop in female patients with IHD. Our findings were in agreement with the study by Al-Bidri et al. [14].

We found no significant association between fibromyalgia and the duration of IHD; this might be explained by the relatively small sample size. Furthermore, there was no significant association between fibromyalgia and statin usage. These findings are in agreement with the previous studies [14], [15].

Among other factors, we found that fibromyalgia was more common in patients with the present myocardial infarction, in patients who had previous coronary angiography, and with the lower LVEF. Based on these findings, it is tempting to suggest that patients with more severe IHD are more likely to develop reactive depression. In addition, significant sleep disturbances had been reported in patients with IHD, and these disturbances were more pronounced with increasing severity of IHD [22]. Therefore, it is plausible that both depression and sleep disturbances might contribute to the development of comorbid fibromyalgia.

Scores on $\mathrm{BDI}$ were significantly higher in the IHD patients with comorbid fibromyalgia. Whether

Table 4: Multivariate binary logistic regression for the significant variables

\begin{tabular}{|c|c|c|c|c|c|c|c|c|}
\hline \multirow[t]{2}{*}{ Variables } & \multirow[t]{2}{*}{$\mathrm{B}$} & \multirow[t]{2}{*}{ S.E. } & \multirow[t]{2}{*}{ Wald } & \multirow[t]{2}{*}{$\mathrm{df}$} & \multirow[t]{2}{*}{$p$-value } & \multirow[t]{2}{*}{ Odd ratio } & \multicolumn{2}{|c|}{ 95\% C.I. for odd ratio } \\
\hline & & & & & & & Lower & Upper \\
\hline Sex (ref: female) & 1.345 & 0.587 & 5.260 & 1 & 0.022 & 3.839 & 1.216 & 12.121 \\
\hline Age & 0.029 & 0.031 & 0.869 & 1 & 0.351 & 1.029 & 0.969 & 1.094 \\
\hline Previous coronary angiography & -0.824 & 0.653 & 1.591 & 1 & 0.207 & 0.439 & 0.122 & 1.578 \\
\hline Present myocardial infarction & -0.175 & 0.716 & 0.060 & 1 & 0.806 & 0.839 & 0.206 & 3.412 \\
\hline LVEF & -0.086 & 0.032 & 7.034 & 1 & 0.008 & 0.917 & 0.861 & 0.978 \\
\hline BDI & 0.039 & 0.040 & 0.994 & 1 & 0.319 & 1.040 & 0.963 & 1.124 \\
\hline Constant & 1.577 & 2.636 & 0.358 & 1 & 0.550 & 4.840 & & \\
\hline
\end{tabular}


depression is induced by fibromyalgia or IHD, or it is an independent exacerbating factor for either or both of them is not clear. There is evidence that several pathophysiological link the association between IHD and depression [23]. These include hyperactivity of the noradrenergic and hypothalamic-pituitary-adrenal system, inflammation, abnormal platelet functioning, and endothelial dysfunction [23]. It has been suggested that depression may be a cause or consequence of fibromyalgia [20]. Another suggestion is that some people are predisposed to both depression and pain through a similar pathogenic pathway [20], [24]. Abnormalities of the serotonergic pathway and hypothalamic pituitary adrenal axis might be related to interconnections between depression and fibromyalgia [25], [26].

The main limitation of the present study is the relatively small sample size. Furthermore, we did not assess the educational status of the patients. Despite these limitations, our findings drawattention to a previously under-recognized possible association between these two conditions. Fibromyalgia is a debilitating disorder and thus can add to the morbidity of IHD if present together. It has been shown that fibromyalgia is substantially associated with a degree of stress [27], and chronic stress may lead to persistent activation of the sympathetic nervous system and the hypothalamic-pituitary-adrenal axis [28]. In the presence of reduced coronary perfusion, sympathetic hyperactivity-driven increases in heart rate and myocardial contractility further worsen myocardial ischemia [29]. Assessment of IHD patients for possible fibromyalgia might be recommended to get appropriate rehabilitation and management accordingly. Finally, more studies with a large number of participants would be necessary to determine the association between the two relatively common conditions.

\section{Conclusion}

There is a high frequency of fibromyalgia in patients with IHD. Patients with IHD and comorbid fibromyalgia were more likely to be older, female, and reported more depressive symptoms. Fibromyalgia was also more common in patients with the present myocardial infarction and in those who had previous coronary angiography. Importantly, IHD patients with comorbid fibromyalgia had lower LVEF.

\section{Acknowledgment}

I feel to acknowledge my deep sense of gratitude to doctor Barzan Izzat for his role in reviewing the manuscript linguistically.

\section{References}

1. Goldenberg DL. Fibromyalgia syndrome. An emerging but controversial condition. JAMA. 1987;257(20):2782. https://doi. org/10.1001/jama.257.20.27

PMid:3553636

2. Clauw DJ. Fibromyalgia: A clinical review. JAMA 2014;311(15):1547-55. https://doi.org/10.1001/jama.2014.3266 PMid:24737367

3. Clauw DJ, Arnold LM, McCarberg BH. the science of fibromyalgia. Mayo Clin Proc. 2011;86(9):907-11. https://doi. org/10.4065/mcp.2011.0206

PMid:21878603

4. McBeth J, Jones K. Epidemiology of chronic musculoskeletal pain. Best Pract Res Clin Rheumatol. 2007;21(3):403-25. https://doi.org/10.1016/j.berh.2007.03.003 PMid:17602991

5. Wolfe F, Ross K, Anderson J, Russell IJ, Hebert L. The prevalence and characteristics of fibromyalgia in the general population. Arthritis Rheum. 1995;38(1):19-28. https://doi. org/10.1002/art.1780380104

PMid:7818567

6. O'Connor CM, Gurbel PA, Serebruany VL. Depression and ischemic heart disease. Am Heart J. 2000;140 Suppl 4:63-9. https://doi.org/10.1067/mhj.2000.109979

PMid: 11011350

7. Frasure-Smith $\mathrm{N}$, Lesperance $\mathrm{F}$, Talajic $\mathrm{M}$. Depression following myocardial infarction. Impact on 6-mo survival. JAMA. 1993;270(15):1819-25.

PMid:8411525

8. Rehm SE, Koroschetz J, Gockel U, Brosz M, Freynhagen R, Tolle TR, et al. A cross-sectional survey of 3035 patients with fibromyalgia: Subgroups of patients with typical comorbidities and sensory symptom profiles. Rheumatology (Oxford). 2010;49(6):1146-52. https://doi.org/10.1093/rheumatology/ keq066

PMid:20236955

9. Su CH, Chen JH, Lan JL, Wang YC, Tseng $\mathrm{CH}$, Hsu CY, et al. Increased risk of coronary heart disease in patients with primary fibromyalgia and those with concomitant comorbidity-a Taiwanese population-based cohort study. PLoS One. 2015;10(9):e0137137. https://doi.org/10.1371/journal. pone. 0137137

PMid:26366998

10. Tsai PS, Fan YC, Huang CJ. Fibromyalgia is associated with coronary heart disease: A population-based cohort study. Reg Anesth Pain Med. 2015;40(1):37-42. https://doi.org/10.1097/ AAP. 0000000000000190

PMid:25436616

11. Wolfe F, Clauw DJ, Fitzcharles MA, Goldenberg DL, Häuser W, Katz RS, et al. Fibromyalgia criteria and severity scales for clinical and epidemiological studies: A modification of the ACR preliminary diagnostic criteria for fibromyalgia. J Rheumatol. 2011;38(6):1113-22. https://doi.org/10.3899/jrheum.100594 PMid:21285161

12. BeckAT, Ward CH, Mendelson M, Mock J, Erbaugh J. An inventory for measuring depression. Arch Gen Psychiatry. 1961;4:561-71. https://doi.org/10.1001/archpsyc.1961.01710120031004 PMid:13688369

13. Abdel-Khalek AM. Internal consistency of an Arabic adaptation of the beck Depression Inventory in four Arab countries. Psychol Rep. 1998;82(1):264-6. https://doi.org/10.2466/ pr0.1998.82.1.264 


\section{PMid:9520563}

14. Al-Bidri K, Gorial F, Al-Rawi Z, Yousif M. Prevalence of fibromyalgia in Iraqi patients with Ischemic heart disease. J Fac Med Bagdad. 2009;51:127-9.

15. Ablin JN, Beilinson N, Aloush V, Elkayam O, Finkelstein A. Association between fibromyalgia and coronary heart disease and coronary catheterization. Clin Cardiol. 2009;32(6):E7-11. https://doi.org/10.1002/clc.20308 PMid:18727109

16. RudischB,NemeroffCB.Epidemiologyofcomorbidcoronaryartery disease and depression. Biol Psychiatry. 2003;54(3):227-40. https://doi.org/10.1016/s0006-3223(03)00587-0 PMid:12893099

17. Al-Abbudi SJ, Lami FH, Wady ZA. Prevalence and assessment of severity of depression among ischemic heart disease patients attending outpatient cardiology Department Baghdad Teaching Hospital, Baghdad, Iraq. J Psychiatry. 2018;21:438.

18. Rao M. Depression in the physically III. Prim Psychiatry. 2008; 15:44-50.

19. Blumental JA. Depression and coronary heart disease: Association and implications for treatment. Cleve Clin J Med. 2008;75:48-52. https://doi.org/10.3949/ccjm.75.suppl_2.s48 PMid:18540147

20. Fishbain DA, Cutler R, Rosomoff HL, Rosomoff RS. Chronic pain-associated depression: Antecedent or consequence of chronic pain? A review. Clin J Pain. 1997;13(2):116-37. https:// doi.org/10.1097/00002508-199706000-00006 PMid:9186019

21. Aaron LA, Bradley LA, Alarcon GS, Triana-Alexander M, Alexander RW, et al. Perceived physical and emotional trauma as precipitating events in fibromyalgia. Associations with health care seeking and disability status but not pain severity. Arthritis Rheum. 1997;40(3):453-60. https://doi.org/10.1002/ art. 1780400311

PMid:9082933
22. Madsen MT, Huang C, Zangger G, Zwisler AD, Gögenur I. Sleep disturbances in patients with coronary heart disease: A systematic review. J Clin Sleep Med. 2019;15(3):489-504.

23. Khawaja IS, Westermeyer JJ, Gajwani P, Feinstein RE. Depression and coronary artery disease: The association, mechanisms, and therapeutic implications. Psychiatry (Edgmont). 2009;6(1):38-51

PMid: 19724742

24. Magni G, Moreschi C, Rigatti-Luchini S, Merskey H. Prospective study on the relationship between depressive symptoms and chronic musculoskeletal pain. Pain. 1994;56(3):289-97. https:// doi.org/10.1016/0304-3959(94)90167-8

PMid:8022622

25. Kato K, Sullivan PF, Evengård B, Pedersen NL. A populationbased twin study of functional somatic syndromes. Psychol Med. 2009;39(3):497-505. https://doi.org/10.1017/ S0033291708003784

PMid: 18578896

26. Thiagarajah AS, Guymer EK, Leech MT, Littlejohn GO. The relationship between fibromyalgia, stress, and depression. Int $\mathrm{J}$ Clin Rheumatol. 2014;9(4):371-84.

27. Chen JH, Guo M, You Y, Liaw L, Kuo H. Factors affecting fibromyalgia in nantou county. Mid-Taiwan $\mathrm{J}$ Med. 2008;13:136-42.

28. Vargas-Alarcon G, Fragoso JM, Cruz-Robles D, Vargas A, Vargas A, Lao-Villadoniga JI, et al. Catechol-O-methyltransferase gene haplotypes in Mexican and Spanish patients with fibromyalgia. Arthritis Res Ther. 2007;9(5):R110. https://doi. org/10.1186/ar2316

PMid:17961261

29. Grassi G, Seravalle G, Mancia G. Sympathetic activation in cardiovascular disease: Evidence, clinical impact, and therapeutic implications. Eur J Clin Invest. 2015;45(12):1367-75. https://doi.org/10.1111/eci.12553

PMid:26480300 